\title{
BMJ Open Disability and morbidity among older patients in the emergency department: a Danish population-based cohort study
}

\author{
Anette Tanderup, ${ }^{1,2,3}$ Annmarie Touborg Lassen, ${ }^{2,4}$ Jens-Ulrik Rosholm, ${ }^{1,2}$ \\ Jesper Ryg ${ }^{1,2}$
}

To cite: Tanderup A, Lassen AT, Rosholm J-U, et al. Disability and morbidity among older patients in the emergency department: a Danish population-based cohort study. BMJ Open 2018;8:e023803. doi:10.1136/ bmjopen-2018-023803

- Prepublication history and additional material for this paper are available online. To view these files, please visit the journal online (http://dx.doi. org/10.1136/bmjopen-2018023803).

Received 3 May 2018 Revised 8 0ctober 2018 Accepted 12 October 2018

Check for updates

(C) Author(s) (or their employer(s)) 2018. Re-use permitted under CC BY-NC. No commercial re-use. See rights and permissions. Published by BMJ.

${ }^{1}$ Department of Geriatric Medicine, Odense University Hospital, Odense, Denmark ${ }^{2}$ Department of Clinical Research, University of Southern Denmark, Odense, Denmark ${ }^{3}$ OPEN, Odense Patient Data Explorative Network, Odense University Hospital, Odense, Denmark

${ }^{4}$ Department of Emergency Medicine, Odense University Hospital, Odense, Denmark

Correspondence to

Anette Tanderup;

Anette.tanderup@rsyd.dk

\section{ABSTRACT}

Objectives The objective was to describe the prevalence of geriatric conditions among older medical patients in the emergency department (ED) and the association with admission, mortality, reattendance and loss of independency.

Design Population-based prospective cohort study. Setting ED of a large university hospital.

Participants All medical patients $\geq 65$ years of age from a single municipality with a first attendance to the ED during a 1-year period (November 2013 to November 2014). Primary and secondary outcome measures Based on information from healthcare registers, we defined geriatric conditions as disability, recently increased disability, polypharmacy and comorbidity. Outcomes were admission, length of admission, 30 days postdischarge mortality, 30 days hospital reattendance and home care dependency 0-360 days following ED contact.

Results Totally, 3775 patients ( $55 \%$ women) were included, age 78 (71-85) years (median (IQR)). No patients were lost to follow-up. The prevalence of 0-4 geriatric conditions was $14.9 \%, 27.3 \%, 25.2 \%, 22.3 \%$ and $10.3 \%$, respectively. The number of conditions was significantly associated with hospital admission, length of admission, 30 days postdischarge mortality and 30 days hospital reattendance. Among patients with no geriatric conditions, $70 \%$ lived independent all 360 days after discharge, whereas all patients with $\geq 3$ conditions had some dependency or were dead within 360 days following discharge.

Conclusion Among older medical patients in the ED, $50 \%$ had two or more geriatric conditions which were associated with poor health outcomes. This highlights the need for studies of the effect of geriatric awareness and competences in the ED.

\section{INTRODUCTION}

In the future, we can expect an increase in the proportion of older medical patients in the emergency department (ED) due to the demographic changes. ${ }^{1}{ }^{2}$ Increased mortality, institutionalisation, hospital reattendance, functional impairment and loss of independency are some of the potential severe outcomes associated with hospitalisation for some of these older patients. ${ }^{3-8}$

\section{Strengths and limitations of this study}

- This population-based cohort study from a Danish municipality was based on data from several Danish national registers with high-quality data.

- A major strength was the complete coverage of a large municipality, the complete follow-up and high data quality.

- Home care was registered during delivery giving data a large conformity with reality.

- The study was a single centre which may reduce the generalisability of the results.

- Several other geriatric conditions, than the ones used in the present study, exist.

Comprehensive geriatric assessment (CGA) is a multidimensional evidence-based assessment that has the potential to improve the prognosis for geriatric patients in the hospital settings ${ }^{9}$ including the acute settings. ${ }^{10}$ It is a balance to identify patients who are neither too well (completely functional independent without medical comorbidities) nor too sick (terminal illness) to benefit from CGA. ${ }^{11}$

Geriatric patients are usually 65 years or older but are not solely defined by age. Instead, geriatric patients are better characterised by the presence of acute and chronic diseases combined with age-related changes, polypharmacy, and social problems and due to these combinations often derived physical and cognitive impairment. ${ }^{12}$ About $25 \%$ of older patients in the ED have cognitive impairment as a result of delirium, dementia or both ${ }^{13}$ polypharmacy is present in $37 \%$, and $39 \%$ have functional decline before the ED contact. ${ }^{14}$ Geriatric patients often present with non-specific complaints like general weakness, immobilisation, confusion or fall. Among patients presenting with non-specific complaints, it is difficult to identify the correct diagnosis and these patients are at risk of wrong triage, admission and longer hospital stay. ${ }^{15-18}$ The presence of medical, 
physical, cognitive and social problems make geriatric patients vulnerable (frail) and at increased risk of poor health outcomes when consulting the ED. ${ }^{12}$ During the past decade, frailty has been the focus of intense research in risk prediction and a large number of risk or frailty indices have been developed. ${ }^{19}$ Depending on the population, setting and the definition $5 \%-30 \%$ of the patients in the ED are characterised as frail. ${ }^{20}{ }^{21}$ Most indices, including validated indices used in the $\mathrm{ED},{ }^{22-25}$ use geriatric conditions like disability (cognitive and physical), polypharmacy and comorbidity when evaluating frailty. ${ }^{19}$ Furthermore, these conditions are also major conditions targeted in CGA. ${ }^{11}$

The cumulated prevalence of these geriatric conditions among older patients in the ED is not well known. Therefore, the objective of this study was to describe the prevalence of geriatric conditions among older medical patients attending the ED and the prognosis associated with these conditions.

\section{METHOD}

\section{Study design and setting}

We conducted a population-based cohort study with 360 days follow-up after an acute medical ED contact.

Odense University Hospital in Denmark is a 1000-bed university teaching hospital with all specialties represented including geriatric medicine. The ED serves a mixed rural-urban population and has a primary catchment area of 288200 persons including Odense municipality. It is the only ED in this area and it provides 24 hours acute medical care. Odense municipality has a population of 168731 adult citizens with $20 \%$ being 65 years or older. ${ }^{26}$ Patients arrive by ambulance following an emergency call or are referred from primary care. All acute patients are received in the ED except patients with prehospital identified cardiovascular disease, ongoing nephrological or oncological treatment. The ED uses a four-level adaptive process triage where triage category is assigned based on main complaint and vital signs. ${ }^{27}$ The main complaint is registered before any diagnostic proceedings are performed. A total of 40 main complaint categories are used (online supplementary 1). From the $\mathrm{ED}$, patients are either admitted to in-hospital treatment or discharged home.

In the Danish healthcare system, primary care services are well established and free of charge for all residents. The municipalities deliver all kind of home care services to older or disabled people. Home care consists of general nursing care and care to support activities of daily living. Type and amount of home care are based on an individual plan generated in collaboration with a specialised nurse. Staffs do on-location registration of time and task, and changes are adjusted continuously with 1-day notice. Data are automatically transferred to a personal electronic citizen record. The municipality also administers residential care like permanent and temporary nursing homes.

\section{Participants}

All consecutive patients 65 years or older living in Odense municipality with a first time acute medical contact to the ED at Odense University Hospital during the period 1 November 2013 to 31 October 2014 were included. Patients dead on arrival to the ED were excluded.

\section{Data source}

The Danish Civil Registration System

The Danish Civil Registration System (CRS) has since 1968 assigned a unique 10-digit civil personal registry number to each Danish citizen at birth and to residents on immigration. The CRS covers data on deaths, births, migration, municipality of residence and marital status. ${ }^{28}$ The unique civil personal registry number enables accurate linkage of information from different data sources on an individual level.

\section{The Danish National Patient Register}

Since 1995, the Danish National Patient Register has registered all hospital admissions and all ED contacts. ${ }^{29}$ The registry contains data regarding date of admission and discharge, discharge diagnosis, and admission department.

\section{The electronic hospital record and the ED logistic system}

All patient-related data are registered and stored at an individual level in the electronic hospital record and the ED logistic tool.

\section{Odense University Pharmacoepidemiological Database}

Odense University Pharmacoepidemiological Database is a prescription database. It covers the region of Southern Denmark including the municipality of Odense. Information on redeemed prescriptions is reported on an individual basis from community pharmacies. Only drugs that are reimbursed are covered. ${ }^{30}$

\section{The Municipality Citizen-Record}

All data on type and amount of home care and resident type are registered in the Municipality Citizen-Record on an individual day-to-day level. When residents are in residential care, it is registered as such, with no registration of type or amount of help delivered.

\section{Data variables}

If a patient had more than one acute medical ED contact in the study period, only the first contact was included as the index contact.

\section{Geriatric conditions}

We defined geriatric conditions as disability, recently increased disability, polypharmacy and comorbidity based on frailty indices, ${ }^{22-25}$ geriatric textbooks, conditions assessed in $\mathrm{CGA}^{11}$ and various descriptions of the geriatric discipline.

Disability was defined as receiving home care 1 or more days the last 30 days prior to ED contact or 1 or more days spent in residential care. 
Contacts to the

Emergency Department

for patients aged

65 years or older

$\mathrm{N}=15,870$

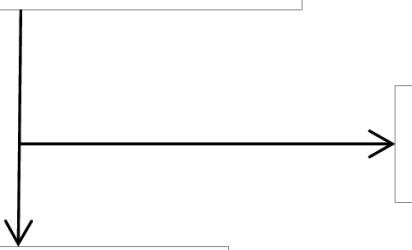

Dead before/at arrival

$\mathrm{N}=7$

Resident outside Denmark

$\mathrm{N}=9$

Acute contacts, alive

and residents in

Denmark

$\mathrm{N}=15,854$

Surgical speciality

$\mathrm{N}=5,966$

Other speciality

$\mathrm{N}=692$

Medical contacts

$\mathrm{N}=9,196$

Not first time medical contact

in the period $\quad \mathrm{N}=2,807$

First medical contact in

the period

$\mathrm{N}=6.389$

Not residents in the municipality of Odense $\mathrm{N}=2,614$

Residents in the municipality of Odense $\mathrm{N}=3,775$

Disability

Recently increased disability

Comorbidity

Polypharmacy
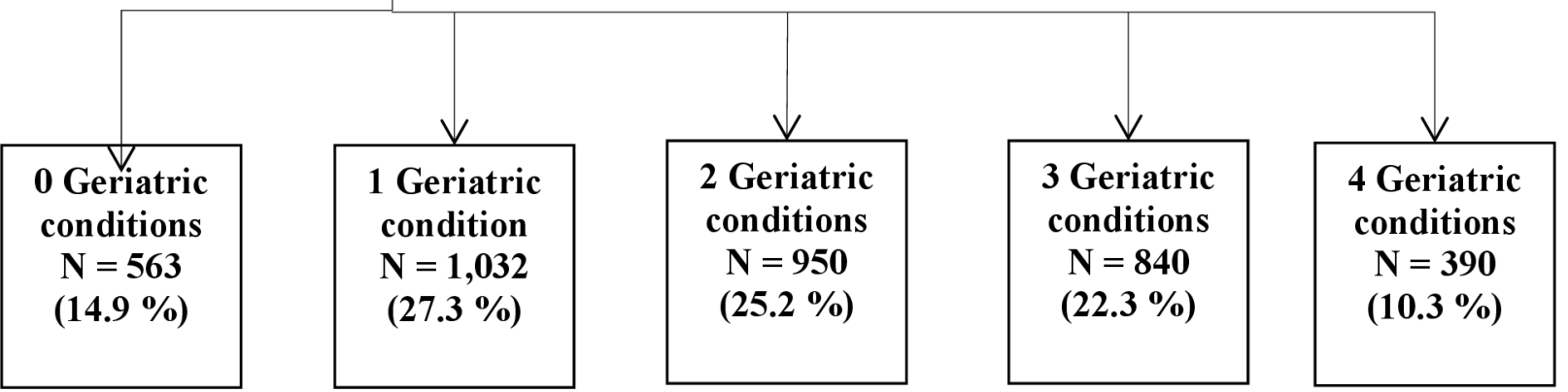

Figure 1 Flow chart of patients included in the study period.

Recently increased disability was defined as increased use of home care (minutes) or more days spent in residential care the last 30 days prior to ED contact compared with the previous 30 days.
Polypharmacy was defined as intake of five or more medications at ED contact. The number of medications with different Anatomical Therapeutic Chemical-codes (fourth level, chemical subgroup) redeemed within 90 


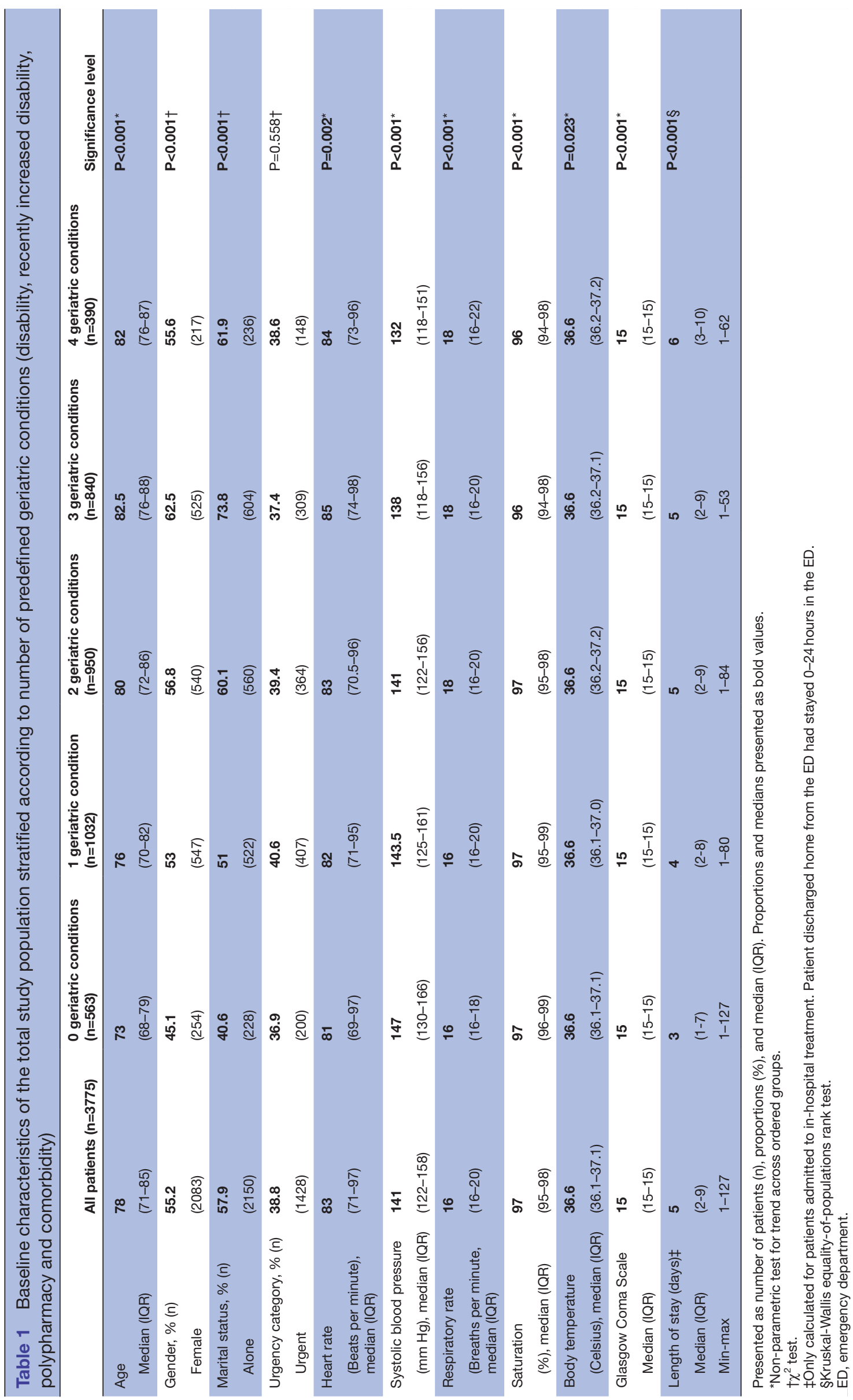




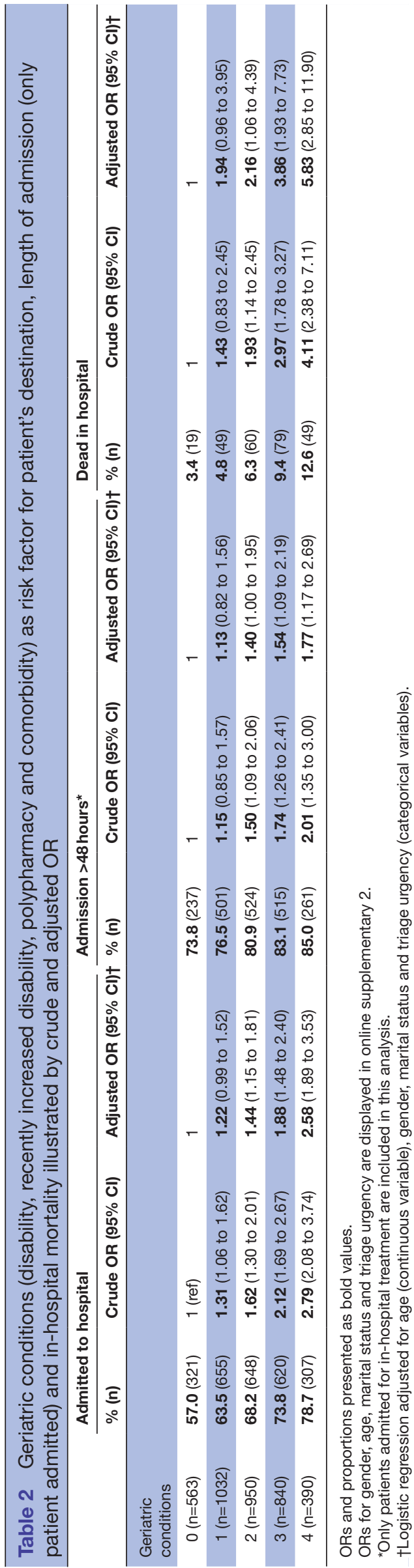

days prior to the ED contact was used to calculate the number of medications at ED contact. ${ }^{30} 31$

Finally, comorbidity was defined as Charlson Comorbidity Index $\geq 2$. Charlson Comorbidity Index was identified by hospital discharge diagnoses from the previous 10 years. $^{32} 33$

All baseline variables and outcome variables were calculated and displayed for the whole study population and for five subpopulations depending on the number of defined geriatric conditions (zero, one, two, three, four or five).

\section{Baseline characteristics}

Baseline characteristics at ED contact included age, gender, marital status, initial triage urgency, vital signs and main presenting complaint at arrival to the ED. Data were extracted from patient records and population-based registers.

Patients' marital status was categorised as 'being with someone' if they were married or had a registered partnership and 'being alone' if they were single, divorced, widower or widow. Urgency category was defined from the initial triage ${ }^{34}$ and was divided in two predefined urgency categories: triage levels 1 and 2 as 'urgent' and triage levels 3 and 4 as 'less urgent'. The 40 main complaints were grouped in two categories 'specific complaint' and 'non-specific complaint'. As Nemec et $a l,{ }^{17}$ we defined a specific complaint as a complaint that provides key information that allows the generation of a working diagnosis and/or treatment protocol, for example, 'chest pain', 'fever' or 'neurological disorder'. Following this, of the 40 predefined main complaints, we defined the following as non-specific complaints 'uncooperative patient', 'delirium', 'falling', 'unspecific illness', 'dizziness' and 'impaired consciousness' (online supplementary 1).

\section{Outcome}

We assessed the following variables as outcomes: Patient's destination (discharged from the ED or admitted to the hospital), length of admission, in-hospital mortality, 30 days postdischarge mortality and hospital reattendance, and 360 days post-discharge dependency of home care (receiving home care or in residential care) and living independent (community dwelling and not receiving any home care at any day in the preceding period). Only acute hospital reattendance (unplanned admission to the hospital or unplanned ED contact) was included in the analyses.

\section{Data analysis and statistical methods}

Data are presented as total and proportions or as medians with IQR. Only medians and (IQR) were calculated due to the skewness of the data distributions. $\chi^{2}$ test was used to test the significance of differences between categorical data. Non-parametric test for trend across ordered groups $^{35}$ was used to test the significance in trend in ordered quantitative non-normal distributed variables. 
Table 3 Geriatric conditions (disability, recently increased disability, polypharmacy and comorbidity) as risk factors of 30 days mortality and 30 days acute hospital reattendance in older patients after discharge from an acute emergency department contact

\begin{tabular}{|c|c|c|c|c|c|c|}
\hline & \multicolumn{3}{|c|}{ Mortality $0-30$ days } & \multicolumn{3}{|c|}{ Acute hospital reattendance $0-30$ days } \\
\hline & $\%$ (n) & $\begin{array}{l}\text { Crude } \\
\text { HR (95\% CI) }\end{array}$ & $\begin{array}{l}\text { Adjusted } \\
\text { HR }(95 \% \mathrm{Cl}) \text { * }\end{array}$ & $\%(n)$ & $\begin{array}{l}\text { Crude } \\
\text { SHR (95\% Cl) }\end{array}$ & $\begin{array}{l}\text { Adjusted } \\
\text { SHR }(95 \% \mathrm{Cl}) \dagger\end{array}$ \\
\hline \multicolumn{7}{|l|}{$\begin{array}{l}\text { Geriatric } \\
\text { conditions }\end{array}$} \\
\hline $0(n=544)$ & $2.2(12)$ & 1 (ref) & 1 & $10.3(56)$ & 1 & 1 \\
\hline $1(n=983)$ & $2.5(25)$ & $\begin{array}{l}1.16(0.58 \text { to } \\
2.30)\end{array}$ & $\begin{array}{l}0.99 \text { (0.48 to } \\
2.05)\end{array}$ & $12.5(123)$ & $\begin{array}{l}1.23(0.90 \text { to } \\
1.69)\end{array}$ & $\begin{array}{l}1.22(0.89 \text { to } \\
1.68)\end{array}$ \\
\hline $2(n=890)$ & $5.4(48)$ & $\begin{array}{l}2.49 \text { (1.32 to } \\
4.68)\end{array}$ & $\begin{array}{l}1.99(1.02 \text { to } \\
3.90)\end{array}$ & $15.3(136)$ & $\begin{array}{l}1.52 \text { (1.11 to } \\
2.07)\end{array}$ & $\begin{array}{l}1.48 \text { (1.08 to } \\
2.03)\end{array}$ \\
\hline $3(n=761)$ & $6.7(51)$ & $\begin{array}{l}3.10 \text { (1.65 to } \\
5.82)\end{array}$ & $\begin{array}{l}2.21 \text { (1.12 to } \\
4.35)\end{array}$ & $19.3(147)$ & $\begin{array}{l}1.95 \text { (1.44 to } \\
2.65)\end{array}$ & $\begin{array}{l}1.93 \text { (1.40 to } \\
2.65)\end{array}$ \\
\hline $4(n=341)$ & $10.6(36)$ & $\begin{array}{l}5.02(2.61 \text { to } \\
9.64)\end{array}$ & $\begin{array}{l}3.75 \text { (1.87 to } \\
7.52)\end{array}$ & $23.8(81)$ & $\begin{array}{l}2.45 \text { (1.74 to } \\
3.43 \text { ) }\end{array}$ & $\begin{array}{l}2.43 \text { (1.72 to } \\
3.42)\end{array}$ \\
\hline
\end{tabular}

HRs, SHRs, and proportions presented as bold values.

HR and SHR for gender, age, marital status and triage urgency are displayed in online supplementary 3 .

${ }^{*}$ Cox proportional hazard model adjusted for age (continuous variable) and number of geriatric conditions, gender, marital status and triage urgency as categorical variable.

†Competing risks regression model adjusted for age (continuous variable) and number of geriatric conditions, gender, marital status and triage urgency as categorical variable.

SHR, sub-HR.

For conditions considering hospitalisation (discharge from the ED or admitted to the hospital, length of hospital admission ( $\leq 48$ hours or $>48$ hours) and in-hospital mortality), we used multivariate logistic regression with numbers of identified geriatric conditions as the independent variable adjusted for predefined variables (age (continuous variable), gender, marital status and triage urgency level (categorical variables)). The dichotomisation of admission length into $\leq 48$ hours and $>48$ hours of admission was chosen due to the organisation of admissions in the ED of Odense University Hospital. When patients are expected to have a short admission ( $\leq 48$ hours), they are admitted to a short time observation unite placed in relation to the ED. Patients with expected $>48$ hours of admission are admitted to an in-hospital ward. If patients with expected short admission are in need of a longer admission, they are transferred to an in-hospital ward. This division into short-stay and longstay units is also seen in other hospitals. ${ }^{36}$

Following discharge, risk factors for mortality were evaluated by Cox regression analysis and presented as unadjusted and adjusted HRs with 95\% CIs for the time period 0-30 days after discharge. Patients were followed to date of death, emigration or end of follow-up, whichever occurred first. In the regression analysis, we defined numbers of identified geriatric conditions as the independent variable adjusted for predefined variables (age (continuous variable), gender, marital status and triage urgency level (categorical variables)) .

Risk factors for a new acute hospital reattendance 0-30 days after discharge were analysed using competing risks methodology with hospital reattendance as the event of interest and death due to any cause as the competing event. In the competing risk analysis, we defined numbers of identified geriatric conditions as the independent variable adjusted for predefined variables (age (continuous variable), gender, marital status and triage urgency level (categorical variables)).

Missing data were treated as such. No data were missing on mortality, municipality healthcare, number of medications, comorbidity and hospital reattendance. Data on marital status were missing in 43 patients and data on urgency category were missing in 97 patients. Data on main complaint were missing in 257 patients.

Sensitivity analyses in regression analysis were done with missing data on urgency replaced by 'urgent' or 'less urgent' for urgency category and with missing data on marital status replaced by 'being alone' and 'not alone'.

All calculations were performed using Stata Release V.15.0 (StataCorp).

The reporting of this study conforms to the Strengthening the Reporting of Observational Studies in Epidemiology statement. ${ }^{37}$

\section{Patient and public involvement}

Patients and/or public were not involved in the development, design, recruitment or conduct of the study.

\section{RESULTS}

Participants

Among the 6389 first time medical contacts for older patients to the ED in the study period, a total of 3775 


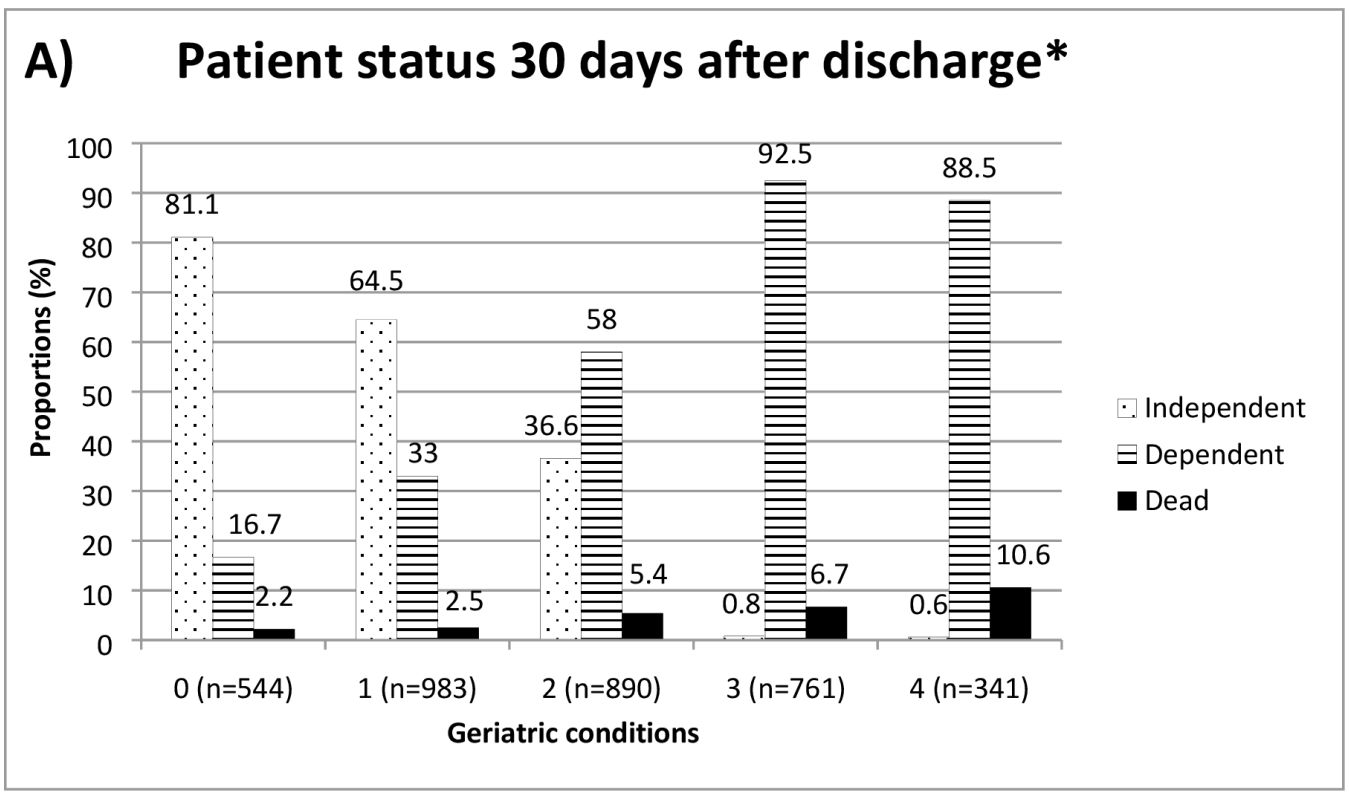

\section{B) Patient status $\mathbf{3 6 0}$ days after discharge*}

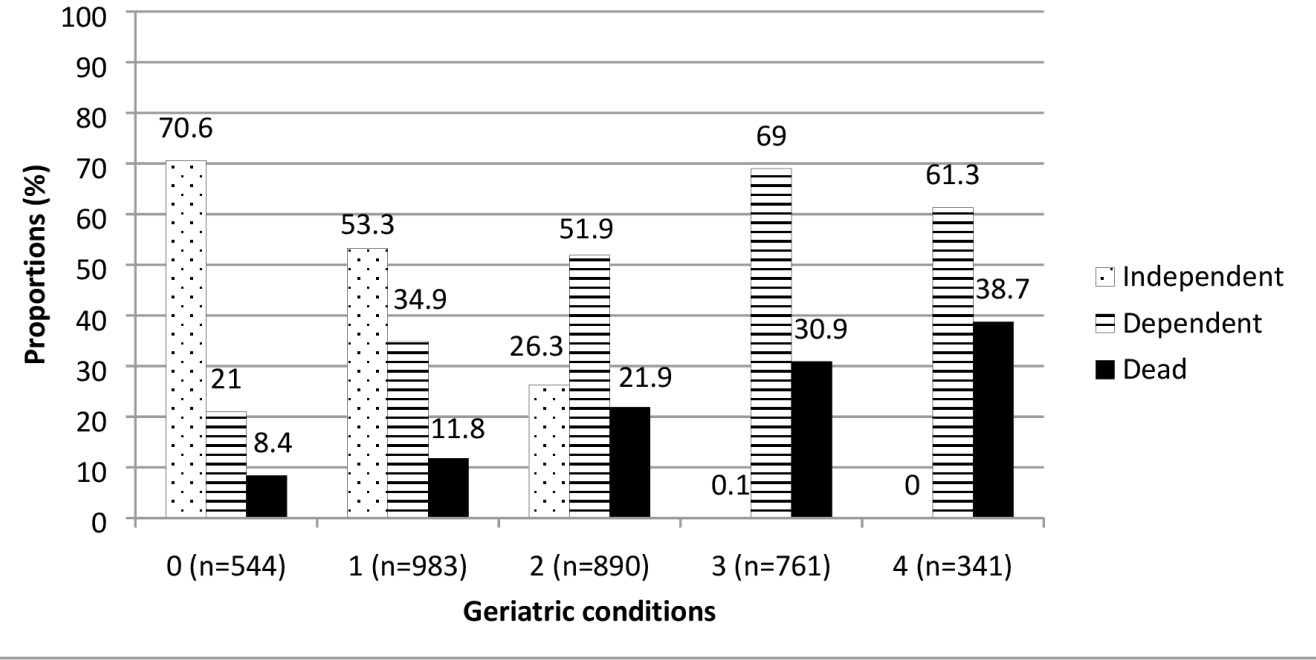

* Only patients discharged alive $(n=3,519)$

Figure 2 The proportion of patients discharged alive who died were dependent on home care or were independent of home care in relation to the number of geriatric conditions (disability, recently increased disability, polypharmacy and comorbidity) in the (A) 30 days period after discharge (B) 360 days period after discharge.

patients were citizens in Odense municipality and included in the study (figure 1).

\section{Baseline characteristics}

Median (IQR) age of included patients was 78 (71-85) years and $55 \%$ were female. Median Charlson Comorbidity Index was 1 (0-3), the median number of medications at ED contact was $5(3-8)$ and $38.8 \%$ were categorised in the triage as urgent at arrival (table 1). Of the 3775 patients, $14.9 \%$ had no geriatric conditions, $27.3 \%$ had one geriatric condition, $25.2 \%$ had two geriatric conditions, $22.3 \%$ had three geriatric conditions and $10.3 \%$ had all four geriatric conditions. The most frequent geriatric condition was polypharmacy (64.3\% of the patients), followed by disability (51.1\%), comorbidity $(49.5 \%)$ and recently increased disability (20.8\%).

With an increasing number of geriatric conditions, patients were older, more were female and more were alone. In parallel, there was a trend that patients with a high number of geriatric conditions had a higher respiratory rate, higher body temperature, higher heart rate, lower arterial oxygen saturation, lower systolic blood pressure and lower Glasgow Coma Scale, but no difference 
was observed in the median of Glasgow Coma Scale and body temperature. There was no difference in triage urgency category in relation to the number of geriatric conditions (table 1).

At arrival to the ED, $11 \%$ of patients were registered with non-specific complaints. No differences were seen in the distribution of specific and non-specific complaints across different numbers of geriatric conditions. Details are presented in online supplementary 1.

\section{Outcome}

An increasing amount of geriatric conditions were significantly associated with increasing odds for hospital admission, hospital stay $>48$ hours and in-hospital mortality (table 2). Compared with patients without any geriatric conditions, those with four geriatric conditions had an OR of 2.58 (95\% CI 1.89 to 3.53) for hospital admission, an OR of 1.77 (95\% CI 1.17 to 2.69) for admission lasting over 48 hours and an OR of 5.83 (95\% CI 2.85 to 11.90) for dying during hospitalisation (table 2).

In the multivariate analysis, an increasing number of geriatric conditions increased the HR for 30 days postdischarge mortality almost four times for patients with four conditions compared with patients with no conditions (table 3). Compared with patients with no conditions, the risk of 30 days hospital reattendance increased progressively to $1.5,1.9$ and 2.4 in patients with two, three and four conditions, respectively (table 3 ).

Sensitivity analysis for missing data did not show any significant differences for OR, HR or sub-HR.

Figure 2 presents patient status (dead, dependent or independent of home care) within the first 30 days after discharge (figure 2A) and 360 days after discharge (figure 2B). Among patients with no geriatric conditions at arrival to the ED, $70 \%$ of the patients lived independent all 360 days after discharge, $53 \%$ of patients with one geriatric condition, $26 \%$ of patients with two geriatric conditions and none of the patients with three or four geriatric conditions lived independently (figure 2B). Among all patients discharged alive $(\mathrm{n}=3519)$, the overall mortality during the entire 360 days follow-up period were $20.6 \%$. A total of $38.7 \%$ of the patients with four geriatric conditions at arrival to the ED were dead 360 days after discharge (figure 2B).

\section{DISCUSSION}

Our study showed that more than $50 \%$ of all patients 65 years or older attending the ED with an acute medical complaint had two or more geriatric conditions. Furthermore, the amount of conditions was closely related to prognosis. By assigning four basic geriatric conditions to patients, we were able to identify patients at high risk of admission, long hospital stay, in-hospital mortality, postdischarge mortality, acute hospital reattendance and loss of independency.

These findings correspond well with other studies assessing functional dependency, comorbidity and polypharmacy as predictors of poor health outcomes like in-hospital mortality, long hospital stay, postdischarge mortality and hospital reattendance. ${ }^{438-41}$

The aim of this study was not to develop a new tool in order to identify frail older patients in the ED or to show when older ED patients should receive specialist assessment like CGA. The aim was to assess and describe the potential size of the problem. Our results showed a substantial overlap between the $95 \%$ CI between the numbers of geriatric conditions, which also indicate that it would not be possible to use the number of geriatric conditions to identify the individual patient at risk of poor health outcome. As the proportion of older patients in the ED increases the importance of geriatric assessment and geriatric emergency medicine might increase. One way of implementing geriatric emergency medicine would be to develop special geriatric EDs, like paediatric EDs and psychiatric EDs. ${ }^{42-44}$ However, a great effort, at least in Denmark, has been done to unite the attendance of acute medical patients at one place, to ensure the same level of treatment regardless of time and place. ${ }^{45}$ Another way could be to increase the geriatric knowledge among ED physicians. ${ }^{46-48}$ Education of ED physicians increases their knowledge but the effect has shown to be limited. ${ }^{49}{ }^{50} \mathrm{~A}$ third model of implementing geriatric emergency is the presence of geriatricians in the ED. This allows a two-step procedure to identify geriatric patients at risk of poor outcome and subsequently applying full geriatric assessment. ${ }^{5152}$ By applying an age-related visitation only for patients to receive geriatric assessment, the patients in most need of geriatric healthcare skills might not be identified. Instead, a 'need-related' visitation seems more accurate. ${ }^{53}$ However, how to identify the patients in need of geriatric assessment remains unclear. Using frailty scales as risk stratification tools might be a possibility. ${ }^{54}$ Several frailty rating scales exist ${ }^{19}$ and screening appears to predict the risk of mortality, ${ }^{56}$ length of admission ${ }^{57}$ and risk of readmission ${ }^{57}$ depending on the frailty scale used. The definition of the frail patient is ambiguously and unfortunately the lack of intervention studies questions the effectiveness of such frailty screening. ${ }^{58}{ }^{59} \mathrm{We}$ used easily accessible data already available at ED contact to identify the described geriatric conditions. This might be effective in the time-restricted setting since no direct assessment is needed to identify these conditions and information is insured even if patients are cognitively impaired. Like the electronic Frailty Index developed to identify frail older patients in general practice, ${ }^{60}$ it might be possible to generate an electronic Frailty Index in the ED using an already developed Frailty Index like the Rockwood accumulation of deficits model. ${ }^{23}$ To ease communication and transition between healthcare sectors, an index should be applied uniformly across different healthcare systems. Further research is needed in order to develop such an instrument.

The prevalence of non-specific complaints varies between studies from $5.5 \%$ to $21 \%{ }^{176162}$ and is more common in frail older patients. ${ }^{63}$ In our study, the 
prevalence of older patients presenting with non-specific complaints was $11 \%$. This might be due to differences in the study populations. Vanpee et $a l^{61}$ only included patients 75 years or older and Nemec et $a l^{17}$ only included patients in the medium triage category. We included all patients $\geq 65$ years of age. We were not able to detect any differences between the prevalence of non-specific complaints and the numbers of geriatric conditions but among patients with disability, a higher prevalence of non-specific complaints was found (data not shown). This might be because functional impairment and presentation with non-specific complaints are somehow related. ${ }^{64}$ Studies reporting the prognosis of patients presenting to the ED with non-specific complaints are conflicting. ${ }^{176265}$ We were not able to show an increased risk of neither in-hospital nor 30 days mortality in patients with non-specific complaints compared with patients with more specific complains (data not shown).

Trends seen in the measurements of systolic blood pressure, respiratory rate, heart rate and arterial oxygen saturation across an increasing number of conditions correspond with already existing knowledge regarding vital signs in older age ${ }^{66}$ However, abnormal or normal vital signs in older patients should always be interpreted with caution since age-related impaired physical regulation, common illness and medications taking by older patients often affects the range of vital sign measurements. ${ }^{66}$ Even though we found a trend, the observed differences among groups did not yield clinical meaningful differences.

\section{Limitations and strengths}

The strengths of this study were the longitudinal cohort design, the large sample size and the accurate cross-sectional linkage between prehospital healthcare data, hospital data and healthcare population-based registries. To minimise bias, we included all consecutive medical ED contacts, the proportion of missing data were very low and follow-up was complete. Home care was always and only registered if it was delivered, giving data a large conformity with reality.

Our study also had some limitations. First, it is a Danish single-centre study and should be interpreted as such. Second, Charlson Comorbidity Index was calculated from information on discharge diagnosis, implying that for a given comorbidity to be recognised it had to require hospitalisation with coding for the comorbidity leading to risk of under-reporting. Also, Charlson Comorbidity Index does not include common comorbidities seen in older patients like osteoporosis, hypertension and atrial fibrillation, and defining comorbidity as Charlson Comorbidity Index $\geq 2$ might also lead to under-reporting. However, it has been shown that the validity of using Danish National health registers to calculate Charlson Comorbidity Index is good and that it is a well-established predictor of mortality and functional impairment even among nursing home patients. ${ }^{336768}$ Third, categorisation of patients not receiving home care as not disabled might be misleading. They might have a healthy spouse taking care of them. Fourth, Odense University Pharmacoepidemiological Database only covers reimbursed medications and not drugs that are dispensed over the counter. This might lead to risk of under-reporting of number of medications taken. Finally, several of the covariate estimates changed direction during the modelling process which suggests collinearity issues or possible effect modification in the multivariate analysis and the results have to be interpreted with this in mind.

\section{CONCLUSION}

Among the older medical ED population, the prevalence of patients with geriatric conditions is high and associated with poor hospital and postdischarge outcomes. The literature supports the presence of geriatricians in existing ED's thereby implying the principles of geriatric medicine in the acute setting. Our study emphasises the potential need of geriatric awareness but does not allow any conclusions regarding effect of geriatric interventions. More focus is needed on how to precisely identify the geriatric patients in the ED who might benefit from applying geriatric assessment and the effect of interventions on both patients and service outcome.

Acknowledgements We would like to thank Niels Ibsgaard Agerbek (Odense University Hospital) and Oskar Bak (Odense municipality) for professional help with data extraction.

Contributors All authors participated in the design of the study. AT performed the statistical analyses in a dialogue with ATL, JR and J-UR. AT wrote the manuscript. All authors were involved in the interpretation of data and the critical revision of the manuscript. AT had the primary responsibility for the final content. All authors read and approved the final manuscript.

Funding This study was supported by funding from the Odense University Hospital, the Faculty of Health Science at University of Southern Denmark, the Danish National Innovation Foundation, the Velux Foundation, and 'Trygfonden'.

Disclaimer The funders had no involvement in the study design, in the collection, analysis and interpretation of the data, in the writing of the report or in the decision to submit the paper for publication.

Competing interests None declared.

Patient consent Not required.

Ethics approval The study was approved by the Danish Data Protection Agency (J No 14/19990) and the National Committee on Health Research Ethics (Project-ID S-20140031).

Provenance and peer review Not commissioned; externally peer reviewed.

Data sharing statement Due to the Danish Law on personal data, we are not allowed to share data in a public dataset. Access to data from the Danish Health Data Authority requires approval from the Danish Data Protection Agency: https:// www.datatilsynet.dk/english/the-danish-data-protection-agency/introduction-tothe-danish-data-protection-agency/. For access and sharing of data and materials, please contact the corresponding author or the Research Service at the Department of Clinical Research, University of Southern Denmark, 5000 Odense C. Phone: +45 65504051 and we will help you with the process and following provide access to the dataset.

Open access This is an open access article distributed in accordance with the Creative Commons Attribution Non Commercial (CC BY-NC 4.0) license, which permits others to distribute, remix, adapt, build upon this work non-commercially, and license their derivative works on different terms, provided the original work is properly cited, appropriate credit is given, any changes made indicated, and the use is non-commercial. See: http://creativecommons.org/licenses/by-nc/4.0/. 


\section{REFERENCES}

1. Rechel B, Grundy E, Robine JM, et al. Ageing in the European Union. Lancet 2013;381:1312-22.

2. Vilpert S, Ruedin HJ, Trueb L, et al. Emergency department use by oldest-old patients from 2005 to 2010 in a Swiss university hospital. BMC Health Serv Res 2013;13:344.

3. Fløjstrup M, Henriksen DP, Brabrand M. An acute hospital admission greatly increases one year mortality - Getting sick and ending up in hospital is bad for you: A multicentre retrospective cohort study. Eur J Intern Med 2017;45:5-7.

4. Kellett J, Rasool S, McLoughlin B. Prediction of mortality 1 year after hospital admission. QJM 2012;105:847-53.

5. García-Pérez L, Linertová R, Lorenzo-Riera A, et al. Risk factors for hospital readmissions in elderly patients: a systematic review. QJM 2011;104:639-51.

6. Goodwin JS, Howrey B, Zhang DD, et al. Risk of continued institutionalization after hospitalization in older adults. J Gerontol A Biol Sci Med Sci 2011;66:1321-7.

7. Cousins G, Bennett Z, Dillon G, et al. Adverse outcomes in older adults attending emergency department: systematic review and meta-analysis of the Triage Risk Stratification Tool. Eur J Emerg Med 2013;20:230-9.

8. Aminzadeh F, Dalziel WB. Older adults in the emergency department: a systematic review of patterns of use, adverse outcomes, and effectiveness of interventions. Ann Emerg Med 2002;39:238-47.

9. Ellis G, Gardner M, Tsiachristas A, et al. Comprehensive geriatric assessment for older adults admitted to hospital. Cochrane Database Syst Rev 2017;9:Cd006211.

10. Conroy SP, Ansari K, Williams M, et al. A controlled evaluation of comprehensive geriatric assessment in the emergency department: the 'Emergency Frailty Unit'. Age Ageing 2014;43:109-14.

11. Ward KT, Reuben DB. Comprehensive geriatric assessment. 2018 https://www.uptodate.com/contents/comprehensive-geriatricassessment?search=comprehensive $\% 20$ geriatric\%20assessment\& source=search_result\&selectedTitle=1 68\&usage_type=default\& display_rank=1 (cited Apr 2018).

12. Salvi F, Morichi V, Grilli A, et al. The elderly in the emergency department: a critical review of problems and solutions. Intern Emerg Med 2007;2:292-301.

13. Samaras N, Chevalley T, Samaras D, et al. Older patients in the emergency department: a review. Ann Emerg Med 2010;56:261-9.

14. Mion LC, Palmer RM, Anetzberger GJ, et al. Establishing a casefinding and referral system for at-risk older individuals in the emergency department setting: the SIGNET model. J Am Geriatr Soc 2001;49:1379-86.

15. Hertwig R, Meier N, Nickel C, et al. Correlates of diagnostic accuracy in patients with nonspecific complaints. Med Decis Making 2013;33:533-43.

16. Bhalla MC, Wilber ST, Stiffler KA, et al. Weakness and fatigue in older ED patients in the United States. Am J Emerg Med 2014;32:1395-8.

17. Nemec M, Koller MT, Nickel CH, et al. Patients presenting to the emergency department with non-specific complaints: the Basel Non-specific Complaints (BANC) study. Acad Emerg Med 2010;17:284-92.

18. Rutschmann OT, Chevalley T, Zumwald C, et al. Pitfalls in the emergency department triage of frail elderly patients without specific complaints. Swiss Med Wkly 2005;135:145-50.

19. Levers M-J, Estabrooks CA, Ross Kerr JC. Factors contributing to frailty: literature review. J Adv Nurs 2006;56:282-91.

20. Ferguson C, Woodard J, Banerjee J, et al, 2010. Operationalising frailty definitions in the Emergency department- a mapping exercise. British Geriatrics Society Autumn Scientific Meeting:Age and Ageing

21. Conroy S, Dowsing T. The ability of frailty to predict outcomes in older people attending an acute medical unit. Acute Med 2013;12:74-6.

22. McCusker J, Bellavance F, Cardin S, et al. Detection of older people at increased risk of adverse health outcomes after an emergency visit: the ISAR screening tool. J Am Geriatr Soc 1999;47:1229-37.

23. Rockwood $\mathrm{K}$, et al. A global clinical measure of fitness and frailty in elderly people. Can Med Assoc J 2005;173:489-95.

24. Meldon SW, Mion LC, Palmer RM, et al. A brief risk-stratification tool to predict repeat emergency department visits and hospitalizations in older patients discharged from the emergency department. Acad Emerg Med 2003;10:224-32.

25. Mitnitski AB, Mogilner AJ, Rockwood K. Accumulation of deficits as a proxy measure of aging. ScientificWorldJournal 2001;1:323-36.

26. Danmarks Statestik. Statestikbanken.dk [Internet], 2017. www. statistikbanken.dk/BY2.

27. Lindberg S $\varnothing$, Lerche la Cour J, Folkestad L, et al. The use of triage in Danish emergency departments. Dan Med Bull 2011;58:A4301.
28. Schmidt M, Pedersen L, Sørensen HT. The Danish Civil Registration System as a tool in epidemiology. Eur J Epidemiol 2014;29:541-9.

29. Schmidt M, Schmidt SAJ, Sandegaard JL, et al. The Danish National Patient Registry: a review of content, data quality, and research potential. Clin Epidemiol 2015;7:449-90.

30. Hallas J, Hellfritzsch M, Rix M, et al. Odense pharmacoepidemiological database: a review of use and content. Basic Clin Pharmacol Toxicol 2017;120:419-25.

31. Methodology WCCfDS. Structure and principles, 2011. https://www. whocc.no/atc/structure_and_principles/. (cited 26 Dec 2016).

32. Charlson ME, Pompei P, Ales KL, et al. A new method of classifying prognostic comorbidity in longitudinal studies: Development and validation. J Chronic Dis 1987;40:373-83.

33. Thygesen SK, Christiansen CF, Christensen S, et al. The predictive value of ICD-10 diagnostic coding used to assess Charlson comorbidity index conditions in the population-based Danish National Registry of Patients. BMC Med Res Methodol 2011;11:83.

34. Lethvall S, Nordberg M, Castrén M. The validity of the triage system ADAPT. Scand J Trauma Resusc Emerg Med 2010;18:36.

35. Cuzick J. A Wilcoxon-type test for trend. Stat Med 1985;4:87-90.

36. Damiani G, Pinnarelli L, Sommella L, et al. The Short Stay Unit as a new option for hospitals: A review of the scientific literature. Medical Science Monitor 2011;17:SR15-SR19.

37. Vandenbroucke JP, von Elm E, Altman DG, et al. Strengthening the Reporting of Observational Studies in Epidemiology (STROBE): Explanation and elaboration. Int J Surg 2014;12:1500-24.

38. Matzen LE, Jepsen DB, Ryg J, et al. Functional level at admission is a predictor of survival in older patients admitted to an acute geriatric unit. BMC Geriatr 2012;12:32.

39. Jónsson PV, Noro A, Finne-Soveri $\mathrm{H}$, et al. Admission profile is predictive of outcome in acute hospital care. Aging Clin Exp Res 2008;20:533-9.

40. Covinsky KE, Justice AC, Rosenthal GE, et al. Measuring prognosis and case mix in hospitalized elders. The importance of functional status. J Gen Intern Med 1997;12:203-8.

41. Levine SK, Sachs GA, Jin L, et al. A prognostic model for 1-year mortality in older adults after hospital discharge. Am J Med 2007;120:455-60.

42. Adams JG, Gerson LW. A new model for emergency care of geriatric patients. Academic Emergency Medicine 2003;10:271-4.

43. Hwang U, Morrison RS. The Geriatric Emergency Department. J Am Geriatr Soc 2007;55:1873-6.

44. Maaravi Y, Stessman J. The geriatric emergency department. J Am Geriatr Soc 2008;56:1579.

45. Sundhedsstyrelsen. Styrket akutberedskab -planlægningsgrundlag for det regionale sundhedsvæsen, 2007.

46. Jones J, Dougherty J, Cannon L, et al. A geriatrics curriculum for emergency medicine training programs. Ann Emerg Med 1986;15:1275-81.

47. Hogan TM, Losman ED, Carpenter CR, et al. Development of geriatric competencies for emergency medicine residents using an expert consensus process. Academic Emergency Medicine 2010;17:316-24.

48. Miller M, Rosenthal RA. Meeting the need for training in geriatrics: the geriatrics education for specialty residents program. J Am Geriatr Soc 2017;65:e142-e145.

49. Biese KJ, Roberts E, LaMantia M, et al. Effect of a geriatric curriculum on emergency medicine resident attitudes, knowledge, and decision-making. Acad Emerg Med 2011;18 Suppl 2:S92-S96.

50. Shah MN, Rajasekaran K, Sheahan WD, et al. The effect of the geriatrics education for emergency medical services training program in a rural community. J Am Geriatr Soc 2008;56:1134-9.

51. McCusker J, Verdon J, Tousignant P, et al. Rapid emergency department intervention for older people reduces risk of functional decline: results of a multicenter randomized trial. J Am Geriatr Soc 2001;49:1272-81.

52. Edmans J, Conroy S, Harwood R, et al. Acute medical unit comprehensive geriatric assessment intervention study (AMIGOS). Trials 2011;12:200.

53. Young $A$. There is no such thing as geriatric medicine, and it's here to stay. Lancet 1989;2:263-5.

54. Conroy S, Parker S. Acute geriatrics at the front door. Clin Med 2017;17:350-3.

55. Ellis G, Marshall T, Ritchie C. Comprehensive geriatric assessment in the emergency department. Clin Interv Aging 2014;9:2033-43.

56. Kojima G, Iliffe S, Walters K. Frailty index as a predictor of mortality: a systematic review and meta-analysis. Age Ageing 2018;47:193-200.

57. Wallis SJ, Wall J, Biram RWS, et al. Association of the clinical frailty scale with hospital outcomes. QJM 2015;108:943-9.

58. Mudge AM, Hubbard RE. Frailty: mind the gap. Age Ageing 2017. 
59. Cesari M, Marzetti E, Calvani R, et al. The need of operational paradigms for frailty in older persons: the SPRINTT project. Aging Clin Exp Res 2017;29:3-10.

60. Clegg A, Bates C, Young J, et al. Development and validation of an electronic frailty index using routine primary care electronic health record data. Age Ageing 2016;45:353-60.

61. Vanpee D, Swine C, Vandenbossche P, et al. Epidemiological profile of geriatric patients admitted to the emergency department of a university hospital localized in a rural area. European Journal of Emergency Medicine 2001;8:301-4.

62. Safwenberg U, Terént A, Lind L. The Emergency Department presenting complaint as predictor of in-hospital fatality. European Journal of Emergency Medicine 2007;14:324-31.

63. Jarrett PG, et al. Illness presentation in elderly patients. Arch Intern Med 1995;155:1060-4.
64. Kellett J, Nickel $\mathrm{CH}$. What are nonspecific complaints and what are their causes and outcomes? The common unknown unknowns of medicine. Eur J Intern Med 2018;47.

65. Quinn K, Herman M, Lin D, et al. Common diagnoses and outcomes in elderly patients who present to the emergency department with non-specific complaints. CJEM 2015;17:516-22.

66. Sjöstrand F, Nickel C. Pitfalls in the Management of Older Patients in the Emergency Department. In: Nickel C, Bellou A, Conroy S, eds. Geriatric Emergency Medicine. Switzerland: Springer International Publishing, 2018:111-3.

67. Bravo G, Dubois MF, Hébert R, et al. A prospective evaluation of the Charlson Comorbidity Index for use in long-term care patients. J Am Geriatr Soc 2002;50:740-5.

68. Frenkel WJ, Jongerius EJ, Mandjes-van Uitert MJ, et al. Validation of the charlson comorbidity index in acutely hospitalized elderly adults: a prospective cohort study. J Am Geriatr Soc 2014;62:342-6. 